\title{
Breast Brachytherapy and a Case Report
}

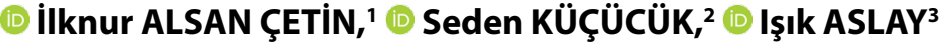 \\ 'Department of Radiation Oncology, Marmara University, İstanbul-Turkey \\ ${ }^{2}$ Department of Radiation Oncology, İstanbul University, İstanbul-Turkey \\ ${ }^{3}$ Department of Radiation Oncology, Acıbadem Hospital, İstanbul-Turkey
}

\begin{abstract}
SUMMARY
For women who had breast-conserving surgery (BCS), brachytherapy can be used along with external beam radiation as a way to add an extra boost of radiation to the tumor site. It may also be used as a form of accelerated partial breast irradiation. Tumor size, location and other factors may affect brachytherapy decision. The patient was 47 years old and applied to Istanbul University Oncology Institute Radiation Oncology Department. A mass in the upper outer quadrant was detected. Invasive ductal cancer was diagnosed with biopsy. MKC and sentinel lymph node biopsy were performed in 2013. Histological and nuclear grade II, ER (+++), PG (+++), cerbB2 (-), lymphovascular invasion (-), pT1N0 was revealed. In 2013, $50 \mathrm{~Gy} / 25$ frx ERT was applied to the left breast tangent. After 16 days, HDR was performed twice daily (BID) (4x3Gy), 14-channel ISI breast implants. The reference dose is defined as 3 Gy GTV.
\end{abstract}

Keywords: Brachytherapy; breast cancer.

Copyright $\odot$ 2019, Turkish Society for Radiation Oncology

\section{Introduction}

Breast-conserving surgery and radiotherapy are the standard treatment methods for early-stage breast cancer. Tumor bed recurrence rate after BCS is $60 \%-85 \%$. Local control increases with a boost of 45-50 Gy and 10-16 Gy.[1,2] Recurrence in breast cancer is often around the tumor. The idea that irradiation of the primary tumor bed instead of the whole breast tissue is sufficient for local control has improved the approach of partial breast radiotherapy.[3,4] Briefly, it is the application of brachytherapy (BRT) within a margin of $1-2 \mathrm{~cm}$ to the primary tumor bed instead of the whole breast tissue. The treatment is completed in as short as 2 weeks with high-dose administration. It also improves patient compliance. This application can be applied in BRT and intraoperatively, and both have advantages and disadvantages. However, most commonly BRT involves interstitial (ISI) and intracavitary practice. Th- ese applications can be in the forms of LDR, HDR, or PDR. Catheters can be intraoperatively or postoperatively placed.

\section{Case Report}

The case patient was aged 47 years who presented to Istanbul University Oncology Institute Radiation Oncology Department. A mass was detected in the upper outer quadrant, and invasive ductal cancer was diagnosed by biopsy. MKC and sentinel lymph node biopsy were performed in 2013. The following findings were revealed: histological and nuclear grade II, ER $(+++)$, PG $(+++)$, cerbB2 $(-)$, lymphovascular invasion $(-)$, and pT1N0. In 2013, 50 Gy/25 frx ERT was applied to the left breast tangent. After 16 days, HDR was performed twice daily $(4 \times 3 \mathrm{~Gy})$, and 14-channel ISI breast implants were used. The reference dose was 3 Gy GTV (Figs. 1-2). 


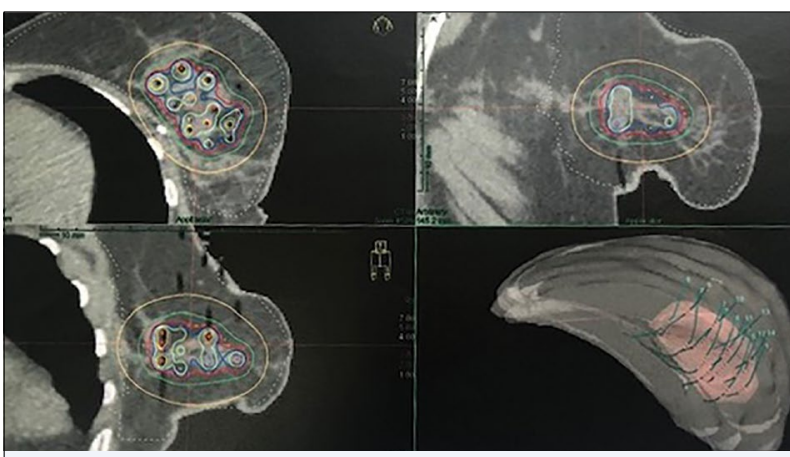

Fig. 1. Dose distribution after breast implantation.

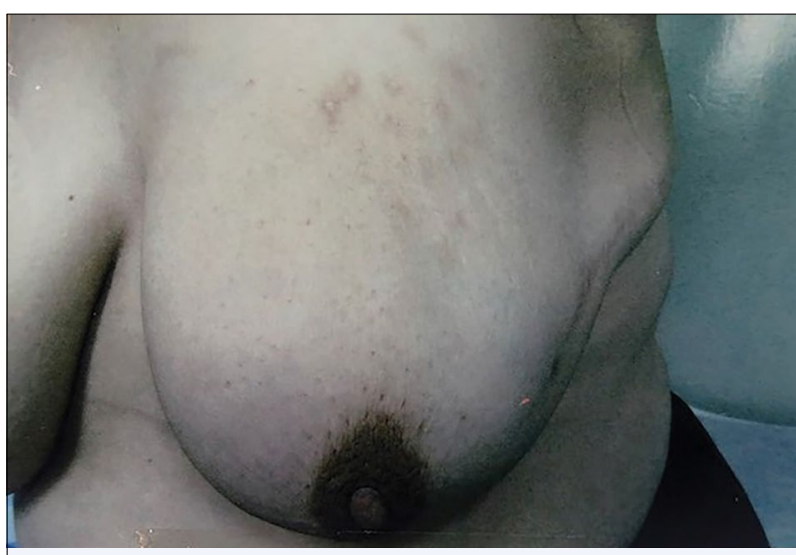

Fig. 2. Cosmetic results after 1 year.

\section{Discussion}

Because of its high-dose distribution, ISI implant is preferred for patients with large mammalian, deep-seated tumors and those with surgical margins.[2] It is recommended to apply 12-20 Gy of 4-6 frx in HDR and be placed in an ISI implant under local anesthesia. In a study by Gabani et al., 175 patients who underwent accelerated partial breast irradiation (APBI) with accelerated ISI-HDR had high survival, local control, and good cosmetic results.[5] In previous randomized studies, no difference was found between ISI-BRT and electron treatments between survival and local control.[6-10]

In intracavitary BRT applications, silicone balloons of 4-6-cm diameter and 1-8 channel catheters can be used. A balloon is inflated with saline after its placement in the lumpectomy cavity. The prescribed dose is planned $1 \mathrm{~cm}$ beyond the surface of the balloon.[11] The most common dose for HDR is $3.4 \mathrm{~Gy}$ for each frx, in total 34 Gy (5 days, twice a day). CT, MR, USG, and clips for CTV definition can be used.[12,13] In breast BRT, treatment of small implant volumes may result in high recurrence.[14] Therefore, a margin of $2 \mathrm{~cm}$ around the lumpectomy cavity is recommended as it increases local control. Excellent cosmetic results and local control were obtained with balloon-based BRT in APBI studies.[11,15] Additionally, Vicini et al. found that a large tumor $(>2 \mathrm{~cm})$ and smaller skin sparing $(<7 \mathrm{~mm})$ were the crucial independent predictors of cosmesis.[13]

\section{Conclusion}

Based on a large number of studies, BRT is considered a safe and effective method for appropriate patients. Since it is an invasive and complicated technique, it should be applied in experienced centers.

Peer-review: Externally peer-reviewed.

Conflict of Interest: The authors have no of interest.

Financial Support: None declared.

Authorship contributions: Concept - İ.A.Ç., S.K., I.A.; Design - İ.A.Ç., S.K., I.A.; Supervision - İ.A.Ç., S.K., I.A.; Materials - İAÇ, S.K., I.A.; Data collection \&/or processing - İ.A.Ç.; Analysis and/or interpretation - İ.A.Ç.; Literature search İ.A.Ç.; Writing - İ.A.Ç., S.K., I.A.; Critical review - İ.A.Ç.

\section{References}

1. Fisher B, Anderson S, Byrant J, Margolese RG, Deutsch M, Fisher ER, et al. Twenty-year follow-up of a randomized trial comparing total mastectomy, lumpectomy, and lumpectomy plus irradiation for the treatment of invasive breast cancer. N Eng J Med 2002;347(16):1233-41.

2. Veronesi U, Cascinelli N, Mariani L, Greco M, Saccozzi R, Luini A, et al. Twenty-year follow-up of a randomized study comparing breast-conserving surgery with radical mastectomy for early beast cancer. $\mathrm{N}$ Engl J Med 2002;347(16):1227-32.

3. Marta GN, Macedo CR, Carvalho HdeA, Hanna SA, da Silva JL, Riera R. Accelerated partial irradiation for breast cancer: systematic review and metaanalysis of 8653 women in eight randomized trials. Radiother Oncol 2015;114(1):42-9.

4. Hepel JT, Wazer DE. A comparation of brachytherapy techniques for partial breast irradiation. Brachytherapy 2012;11(3):163-75.

5. Gabani P, Cry AE, Zoberi JE, Ochoa LL, Matesa MA, Thomas MA, et al. Long-term outcomes of APBI via multicatheter interstitial HDR brachytherapy: Results of a prospective single- institutional registry. Brachytherapy 2018;17(1):171-80.

6. Polgar C, Fodor J, Major T, Sulyok Z, Kasler M. Breastconserving therapy with partial or whole breast irradiation: ten years results of the Budapest randomized trial. Radiother Oncol 2013:108(2):197-202. 
7. Strnad V, Ott OJ, Hildebrandt G, Kauer-Dorner D, Knauerhase H, Major T, et al; Groupe Européen de Curiethérapie of European Society for Radiotherapy and Oncology (GEC-ESTRO). 5-year results of accelerated partial breast irradiation using sole interstitial multicatheter brachytherapy versus whole-breast irradiation with boost after breast-conserving surgery for low-risk invasive and in-situ carcinoma of the female breast: a randomised, phase 3, non-inferiority trial. Lancet 2016;387(10015):229-38.

8. Polgár C, Ott OJ, Hildebrandt G, Kauer-Dorner D, Knauerhase H, Major T, et al; Groupe Européen de Curiethérapie of European Society for Radiotherapy and Oncology (GEC-ESTRO). Late side-effects and cosmetic results of accelerated partial breast irradiation with interstitial brachytherapy versus wholebreast irradiation after breast-conserving surgery for low-risk invasive and in-situ carcinoma of the female breast: 5-year results of a randomised, controlled, phase 3 trial. Lancet Oncol 2017;18(2):259-68.

9. Shah C, Vicini F, Shaitelman SF, Hepel J, Keisch M, Arthur D, et al. The American Brachytherapy Society consensus statement for accelerated partial-breast irradiation. Brachtherapy 2018;17(1):154-70.

10. Rabinovitch R, Winter K, Kuske R, Bolton J, Arthur D, Scroggins T, et al. RTOG 95-17, a Phase II trial to evaluate brachytherapy as the sole method of radiation therapy for Stage I and II breast carcinoma -year- 5 tox- icity and cosmesis. Brachtherapy 2014;13(1):17-22.

11. Vicini FA, Keisch M, Shah C, Goyal S, Khan AJ, Beitsch PD, et al. Factors associated with optimal long-term cosmetic results in patients treated with accelerated partial beast irradiation using balloonbased brachytherapy. Int J Radiat Oncol Biol Phys 2012;83(2):512-8.

12. Sedlmayre F, Rahim HB, Kogelnik HD, Menzel C, Merz F, Deutschmann H, et al. Quality assurance in breast cancer brachytherapy: Geographic miss in the intersititial boost theatment of the tumor bed. Int J Radiat Oncol Bio Phys 1996;34(5):1133-9.

13. Vicini FA, Jaffray DA, Horwitz EM, Edmundson GK, DeBiose DA, Kini VR, et al. Implementation of 3D-virtual brachytherapy in the management of breast cancer: A description of a new method of interstitial brachytherapy. Int J Radiat Oncol Biol Phys 1998;40(3):629-35.

14. Fentiman IS, Poole C, Tong D, Winter PJ, Gregory WM, Mayles HM, et al. Inadequacy of iridium implant as sole radiation treatment for operable breast cancer. Eur J cancer 1996;32A(4):608-11.

15. Cuttino LW, Arthur DW, Vicini F, Todor D, Julian T, Mukhopadhyay N. Long-term results from the contura multilumen balloon breast brachytherapy catheter phase 4 registry trial. Int J Radiat Oncol Biol Phys 2014;90(5);1025-9. 